\title{
Discussion: Stability analysis of earth pressure balance shield tunnel face considering soil arching
}

\section{Keqi Liu}

PhD candidate, Research Center of Geotechnical and Structural Engineering, Shandong University, Jinan, China

\section{Wantao Ding}

Associate Professor, Research Center of Geotechnical and Structural Engineering, Shandong University, Jinan, China (corresponding author: dingwantao@sdu.edu.cn)

\section{Qianqing Zhang}

Professor, Research Center of Geotechnical and Structural Engineering, Shandong University, Jinan, China

\section{Peihe Shi}

Master's candidate, Research Center of Geotechnical and Structural Engineering, Shandong University, Jinan, China

Changgen Yan

Associate Professor, Highway School of Chang'an University, Xi'an, China James Nicholas Shirlaw

Senior Consultant, Golder Associates (Hong Kong) Ltd, Hong Kong, China

\section{Contribution by J. N. Shirlaw}

Liu et al. (2018) presented a new basis for calculating face pressures for pressurised tunnel-boring machine (TBM) tunnelling.

As part of the paper, the authors presented an interesting, but tantalising, case study of a face collapse during earth pressure balance (EPB) TBM tunnelling for the Changsha-ZhuzhouXiangtan intercity railway. The collapse of the face led to a sinkhole forming over the tunnel. In the paper, the authors provide calculations for the horizontal pressure exerted by the soils in the face or the tunnel, and comment on the shape of the failure surface obtained using a numerical model. However, for a case study, there is very little detail on the actual failure or what was happening in the tunnel before and during the failure. Although the authors present the case study in the context of their calculations for face pressure, without more information it is not possible to understand the failure or justify the authors' calculations and related conclusions.

In particular, answers to the following questions would be useful.

What face pressure was being applied by the EPB TBM when the failure occurred?

- For the face to collapse, the face pressure must have been lower than the minimum pressure required for stability; that is, the factor of safety must have been less than 1 . How do the authors' calculations, at a factor of safety of 1, compare with the actual face pressure applied at the time of failure?

- Why was an inadequate face pressure being applied? Was this due to

- incorrect face pressure calculations or, possibly, no face pressure calculations prior to the collapse, or

a were there operational errors by the TBM driver such that the calculated face pressure was not applied?

- What was the plan area and volume of the sinkhole at the surface and were there any adverse consequences, such as damage to buildings, utilities or roads?
Was surface settlement being measured over the tunnel and was there a trend of increasing settlement that might have warned of the impending collapse?

The authors provide measured pressures from the sensors on the TBM in Figure 14 of the paper. The values of the measured pressures are slightly greater than the theoretical minimum pressure required, assuming arching. However, the authors do not state when and where these measured pressures were obtained.

- Were these results obtained during the failure or once tunnelling had restarted after the failure?

- The measured face pressure will vary during each tunnel advance and will also change when the tunnel advance stops for ring building. The data presented in the paper are therefore a snapshot in time, but we are not told when or what activity the data are associated with - during active mining or during ring build?

Any collapse case is interesting: it provides the opportunity to confirm theoretical models, as the factor of safety is known, and to review the practical application of those models. The discusser is seeking to understand whether this collapse was the result of incorrect use of the available theoretical models to establish the necessary face pressure or whether it was due to poor management of the TBM.

\section{Authors' reply}

The authors are grateful for the discusser's interest in our work. A number of important points have been raised that we are delighted to clarify and expand upon.

\section{The action of supporting force}

In order to maintain the stability of a tunnel face, the pressure of the soil chamber needs to be in dynamic balance with the soil and water pressure of the loosening soil, reducing the 
disturbance to strata during the shield tunnelling process. The pressure of the soil chamber includes the lateral pressure produced by the deadweight of the soil in the soil chamber and the support force acting on the confined soil chamber through the pressure plate (Broere, 2001). The force balance mechanism of a tunnel face is shown in Figure 15, in which $\boldsymbol{P}$ is the water and soil pressure in front of tunnel face, $\boldsymbol{P}_{1}$ is the supporting force acting on the soil chamber bearing plate and $\boldsymbol{P}_{2}$ is the lateral compressive stress of the muck in the soil chamber due to gravity. During the process of EPB shield tunnelling, a common way to maintain pressure in the soil chamber is to add bentonite and foam into the chamber (Martinelli et al., 2015), just as in the case study. As long as the muck pressure in the soil chamber is balanced with the water and soil pressure in front of the tunnel face, the tunnel face will remain stable.

The supporting force is applied in different ways for different types of shield (e.g. soil pressure, bentonite mud or compressed air). If the excavation face is unstable and collapses when the shield cutter is being changed, serious casualties will occur. If the pressure applied on the excavation surface is too high, the soil in front of the tunnel face will be pushed out of the ground, resulting in surface uplift. Therefore, in the process of shield construction, it is unreasonable to define the safety factor solely according to the magnitude of the supporting force.

Face stability during the excavation of soft clay ground tunnels has been investigated by many researchers. Based on field data collected during tests, the so-called stability ratio, $N$, was proposed by Broms and Bennermark (1967) to analyse the stability of a tunnel face. Ding et al. (2019) presented a failure mechanism with a multi-zone consisting of four zones, revealing the relationship between the critical value of the stability ratio $N$ and the burial depth (i.e. $C / D$ ) of the tunnel, as well as the weight (i.e. $\gamma D / c_{\mathrm{u}}$ ) of the soil.

\section{Ground surface
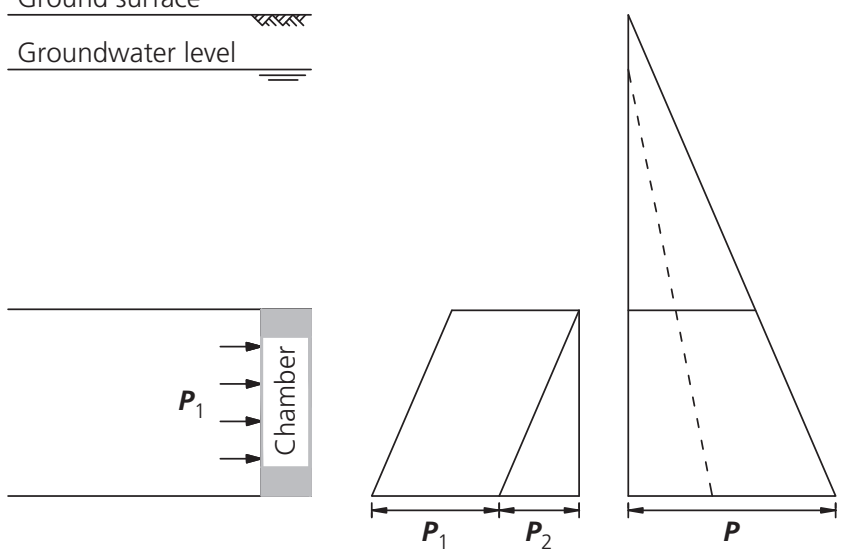

Figure 15. Balance mechanism of supporting forces working at a tunnel face
In the study under discussion (Liu et al., 2018), in order to obtain the limit supporting force of the EPB shield excavation working face in compound strata, a three-dimensional slip instability model was first set up and microelement subdivision was carried out in the individual strata. Then, according to the initial boundary conditions under a specific external load, combined with the theory of the soil arching effect, stress analysis of the first soil microelement was carried out and the stress balance differential equation of the microelement was obtained. A Matlab programme was compiled, the differential equation was solved using the fourth-order Runge-Kutta numerical calculation method and the vertical stress distribution of the microelement was obtained. Then, the lateral stress coefficient according to the minor principal stress arch theory was used to calculate the horizontal compressive stress. Finally, the limit supporting force for tunnel face stability was obtained. For compound strata, because of the differences in the parameters in each layer, different boundary conditions should be established according to the actual situation in the different layers separately, carrying out the above calculation process in a circular manner. The flowchart to calculate the limit supporting force of the tunnel face in compound strata is shown in Figure 16.

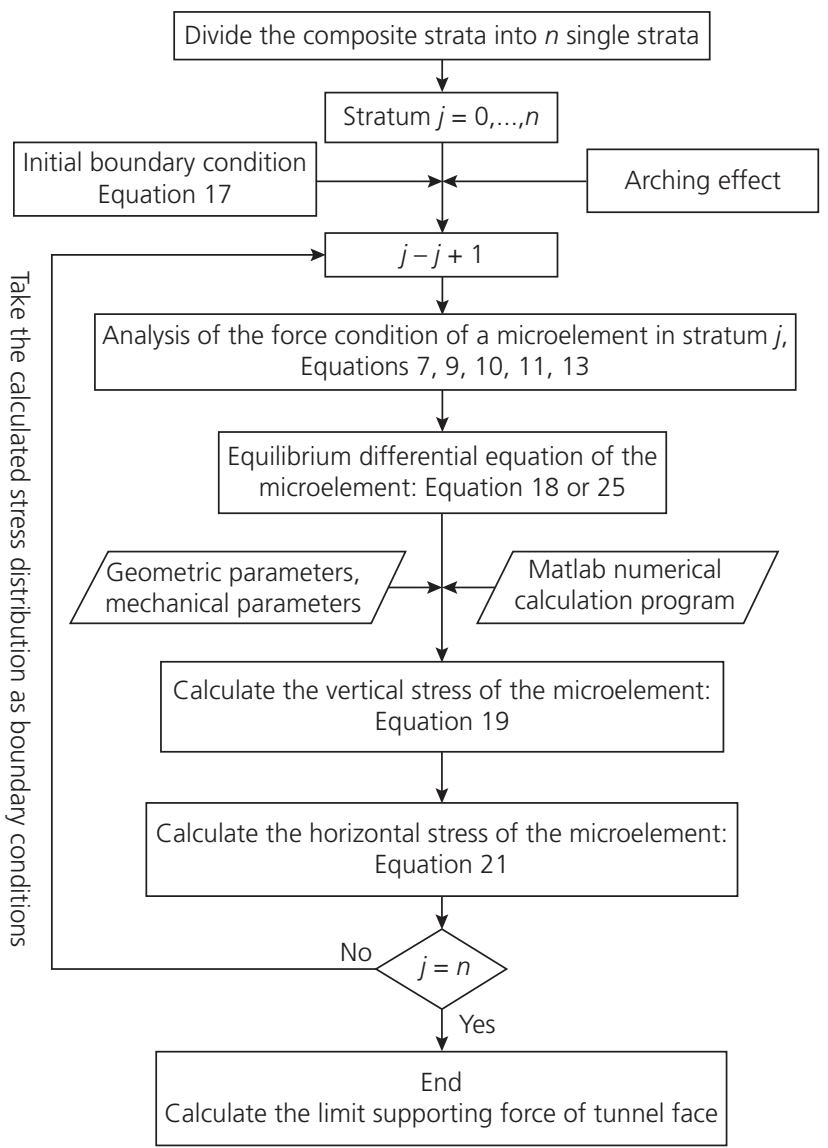

Figure 16. Flowchart for computation of the limit supporting force of a tunnel face in compound strata 
However, in an actual construction process, accurate calculation of the limit supporting force of the tunnel face is very complicated, mainly because the strata conditions are complex, changeable and irregular. State-of-the-art tunnelling in difficult ground conditions and built-up areas still involves a trial-and-error approach as complete understanding of the physics governing the interaction between a TBM and the surrounding soil is still lacking (Festa et al., 2012; Shirlaw, 2016). In addition, even though the limit supporting force of the tunnel face can be accurately calculated, the action form of the supporting force is applied on the soil skeleton of the tunnel face through improved muck. Therefore, the choice of conditioning agent in the sealed cabin is very important. Often, the choice of conditioning agent is set and its control during excavation is made on a trial-and-error basis during the excavation process (Peila et al., 2009).

\section{Failure process description}

The process of the tunnel face instability in the case study is described here. First, a sudden increase in the torque and thrust of the cutter disc in the tunnelling process led to an alarm and shutdown of the shield tunnelling machine. After the jack was unloaded, the cutter disc was restarted and shield tunnelling was resumed. However, the tunnelling parameters were abnormal. In particular, the total thrust of the shield machine was relatively large (about $42000 \mathrm{kN}$ whereas the normal is about $30000 \mathrm{kN}$ ), the tunnelling speed was very slow (about $4 \mathrm{~mm} / \mathrm{min}$ (normal about $30 \mathrm{~mm} / \mathrm{min}$ )) and the cutter disc torque was very large (about $12 \mathrm{MN}$.m (normal about $6.8 \mathrm{MN} . \mathrm{m}$ )), which exceeded the alarm value for the cutter disc torque of the shield machine. During this period, the stability of the tunnel face was considered to be at the limit state, meaning it could collapse at any time. Subsequent developments proved this. Therefore, the pressure in the chamber during this period was recorded and used as the limit supporting force in the theoretical analysis.

Within a short time, a sinkhole $8 \mathrm{~m}$ in diameter and with a central depth of about $50 \mathrm{~cm}$ formed on the surface, corresponding to the top of the cutter disc. Because this surface subsidence occurred in a short period of time, there was not enough time to collect data in the early stage of the subsidence. On the contrary, before destruction of the tunnel face, more abnormal data were collected on the control platform of the shield machine.

What needs to be further explained is that the monitoring data were not much higher than the theoretical calculation values.
The data of monitoring point $1 \#$ were basically consistent with the average value of the theoretical calculation, indicating that the theoretical calculation was reasonable. However, when the soil arching effect was not considered, the theoretical value was obviously larger than the measured value and the numerical result, which proves that it is necessary to consider the soil arching effect in the calculation of the limit supporting force.

Accurate calculation of the limit supporting force is based on accurate knowledge of strata information. The paper only expatiated on the calculation method and did not cover a discussion of the whole tunnelling pressure control technology. In order to ensure smooth tunnelling, an accurate calculation model must be matched with accurate strata information. Without accurate geological parameters, the calculation model is a useless tool. During the process of tunnelling, strata information is always changing, so it is very difficult to input correct calculation parameters into a theoretical model. Obviously, in shield tunnelling, stability control of the tunnel face is a complex and systematic engineering task that must be combined with accurate calculations, advanced technology and a perfect control system.

\section{REFERENCES}

Broere W (2001) Tunnel Face Stability and New CPT Applications. Doctoral thesis, Delft University of Technology, Delft, Netherlands.

Broms BB and Bennermark H (1967) Stability of clay at vertical openings. Journal of the Soil Mechanics \& Foundations Division 93(1): 71-94.

Ding WT, Liu KQ, Shi PH, Li MJ and Hou ML (2019) Face stability analysis of shallow circular tunnels driven by a pressurized shield in purely cohesive soils under undrained conditions. Computers and Geotechnics 107: 110-127.

Festa D, Broere W and Bosch JW (2012) An investigation into the forces acting on a TBM during driving-mining the TBM logged data. Tunnelling and Underground Space Technology 32: $143-157$.

Liu KQ, Ding WT, Zhang QQ, Shi PH and Yan CG (2018) Stability analysis of earth pressure balance shield tunnel face considering soil arching. Proceedings of the Institution of Civil Engineers Geotechnical Engineering, https://doi.org/10.1680/jgeen.18.00052.

Martinelli D, Peila D and Campa E (2015) Feasibility study of tar sands conditioning for earth pressure balance tunnelling. Journal of Rock Mechanics and Geotechnical Engineering 7(6): 684-690.

Peila D, Oggeri C and Borio L (2009) Using the slump test to assess the behavior of conditioned soil for EPB tunneling. Environmental and Engineering Geoscience 15(3), 167-174.

Shirlaw JN (2016) Pressurised TBM tunnelling in mixed face conditions resulting from tropical weathering of igneous rock. Tunnelling and Underground Space Technology 57: 225-240. 